\title{
Significantly association of diabetes mellitus with $C T L A-4$ gene polymorphisms based on a meta-analysis of epidemiological evidence in Asians and non-Asians
}

\author{
J. Liu ${ }^{1,2 *}$, H.X. Zhang ${ }^{3 *}$, G.Y. Feng ${ }^{2}$ and L. He ${ }^{2}$ \\ Neuropsychiatric Disorders, Shanghai Jiao Tong University, \\ Ministry of Education, Shanghai, China \\ ${ }^{3}$ Research Center for Experimental Medicine, \\ *These authors contributed equally to this study. \\ Corresponding author: L. He \\ E-mail: helinhelin3@126.com
}

${ }^{1}$ Shanghai Key Laboratory for Prevention and Treatment of Bone and Joint Diseases with Integrated Chinese-Western Medicine, Shanghai Institute of Orthopaedics and Traumatology, Department of Orthopaedics, Ruijin Hospital, Shanghai Jiao Tong University School of Medicine, Shanghai, China

${ }^{2}$ Bio-X Institute, Key Laboratory for the Genetics of Developmental and

State Key Laboratory of Medical Genomics, Rui-Jin Hospital Affiliated to

Shanghai Jiao Tong University School of Medicine, Shanghai, China

Genet. Mol. Res. 12 (3): 3919-3930 (2013)

Received January 13, 2013

Accepted May 27, 2013

Published September 23, 2013

DOI http://dx.doi.org/10.4238/2013.September.23.11

\begin{abstract}
We evaluated association of polymorphisms in the CTLA4 gene with the risk of type 1 diabetes mellitus. Comprehensive metaanalysis was applied to case-control studies of the association between CTLA-4 and type 1 diabetes mellitus to assess the joint evidence for the association, the influence of individual studies, and evidence for publication bias. We searched PubMed, Medline, Embase, Cochrane Library, and reference lists of relevant studies to February 2012, and made
\end{abstract}


email contact with authors. For the case-control studies, we found 1) support for an association between CTLA-4 and type 1 diabetes mellitus, 2) no evidence that this association was accounted for by any one study, and 3) no evidence for publication bias. In all, although the association between CTLA-4 polymorphisms and type 1 diabetes mellitus is weak, we suggest that it is real. Further studies are needed to clarify what variant of CTLA-4 (or some related gene) accounts for this association.

Key words: Diabetes; $C T L A-4$ gene; Meta-analysis; SNPs

\section{INTRODUCTION}

The CTLA-4 (cytotoxic T-lymphocyte-associated antigen-4) gene is located on the long arm of chromosome $2 \mathrm{q} 33$. It consists of 4 exons and 3 introns. Exon 1 encodes a leader peptide sequence, exon 2 codes for an immunoglobulin domain, and exons 3 and 4 code for the hydrophobic transmembrane domain and the cytoplasmic domain, respectively. This gene encodes a receptor expressed by activated $\mathrm{T}$ cells. This receptor functions as a key negative regulator of $\mathrm{T}$ cell activation. Based on function and experimental data, it has been suggested as a candidate gene for conferring susceptibility to autoimmune disease (Greenwald et al., 2002). In normal immune response, antigen recognition by Th cells is mediated through interaction between $\mathrm{CD} 28$, which is expressed on virtually all $\mathrm{T}$ cells, and B7 proteins on the surface of antigen-presenting cells. This binding between CD28 and B7 is essential for initiating the responses of naïve T cells. In some cases, T cells that encounter self-antigens may begin to express CTLA-4 molecules as a protective mechanism. CTLA-4 molecules have high affinity for B7 molecules and deliver inhibitory signals to T cells. CTLA-4 has a greater affinity for the B7 molecule than does CD28 and it downregulates T-cell function (Leung and Linsley, 1994). Therefore, it may play a crucial role in T-cell-mediated autoimmunity and thus in susceptibility to autoimmune diseases, including T1D.

T1D is the most prevalent form of diabetes in children and young adults and results from autoimmune $\mathrm{CD} 4+$ and $\mathrm{CD} 8+$ T-cell-directed destruction of insulin-producing pancreatic $\beta$-islet cells in genetically susceptible individuals, leading to irreversible hyperglycemia and related complications. Several genes have been associated with the risk of developing T1D, including IDDM12 located on chromosome 2q3; which encodes key lymphocyte co-receptors, including CTLA-4, CD28, and inducible costimulator (ICOS). All of these genes are in close linkage. Many molecular epidemiologic studies have evaluated the potential role of +49A/G (Donner et al., 1997; Van der Auwera et al., 1997; Krokowski et al., 1998; Djilali-Saiah et al., 1998; Awata et al., 1998; Yanagawa et al., 1999; Hayashi et al., 1999; Abe et al., 1999; Takara et al., 2000; Lee et al., 2000; Ihara et al., 2001; Kamoun et al., 2001; Osei-Hyiaman et al., 2001; McCormack et al., 2001; Kikuoka et al., 2001; Cosentino et al., 2002; Fajardy et al., 2002; Cinek et al., 2002; Ma et al., 2002; Klitz et al., 2002; Wood et al., 2002; Ongagna et al., 2002; Mochizuki et al., 2003; Bouqbis et al., 2003; Zalloua et al., 2004; Haller et al., 2004; Ide et al., 2004; Kawoura et al., 2005; Zhernakova et al., 2005; Ahmedov et al., 2006; Baniasadi et al., 2006; Ikegami et al., 2006; Caputo et al., 2007; Saleh et al., 2008; Douroudis et al., 2009; Balic et al., 2009; Jung et al., 2009; Korolija et al., 2009; Ferreira et al., 2009; Benmansour et al., 2010; Ei Wafai et al., 2011; Philip and Isabel, 2011; Mosaad et al., 2012) in susceptibility to type 1 diabetes (T1D). Given the amount of accumulated data, we considered it worthwhile to perform a quantitative synthesis of the evidence. 
To deal with the ambiguities raised by inconsistent results among molecular genetic studies and to examine the putative association between CTLA-4 and T1D, we applied metaanalysis to all available case-control association studies.

\section{MATERIAL AND METHODS}

\section{Identification of eligible studies}

A total of 43 published studies between CTLA-4 and T1D were identified according to our inclusion criteria, involving 8021 cases and 9570 controls (Nistico et al., 1996; Donner et al., 1997; Van der Auwera et al., 1997; Krokowski et al., 1998; Djilali-Saiah et al., 1998; Awata et al., 1998; Yanagawa et al., 1999; Hayashi et al., 1999; Abe et al., 1999; Takara et al., 2000; Lee et al., 2000; Ihara et al., 2001; Kamoun et al., 2001; Osei-Hyiaman et al., 2001; McCormack et al., 2001; Kikuoka et al., 2001; Cosentino et al., 2002; Fajardy et al., 2002; Cinek et al., 2002; Ma et al., 2002; Klitz et al., 2002; Wood et al., 2002; Ongagna et al., 2002; Mochizuki et al., 2003; Bouqbis et al., 2003; Zalloua et al., 2004; Haller et al., 2004; Ide et al., 2004; Ahmedov et al., 2006; Baniasadi et al., 2006; Ikegami et al., 2006; Saleh et al., 2008; Douroudis et al., 2009; Balic et al., 2009; Jung et al., 2009; Korolija et al., 2009; Ferreira et al., 2009; Benmansour el al., 2010; Ei Wafai et al., 2011; Philip and Isabel, 2011; Mosaad et al., 2012). The main characteristics of these studies are described in Table 1. The $+49 \mathrm{~A} / \mathrm{G}$ group was subdivided into 4 subgroups and analyzed (6 studies in Africans, 19 studies in Asians, 3 studies in Americans and 15 studies in Europeans). Sources included MEDLINE and EMBASE (search last updated in February 2012). The search strategy was based on combinations of the terms "CTLA-4", "cytotoxic T-lymphocyte-associated antigen-4", "CD152", and "diabetes". Reference lists in retrieved articles were also screened.

Nonfamilial case-control studies were eligible if the researchers had determined the distribution of genotypes for any of these polymorphisms in T1D cases and disease-free controls. We excluded studies with family-based designs in which the analysis was based on linkage considerations.

\section{Data extraction}

The following information was independently extracted from the identified studies by two participants in the meta-analysis: first author, journal, year of publication, study design, ethnicity of the study population, clinical characteristics, genotyping method, the number of cases and controls or odds ratio (OR) and 95\% confidence interval (CI), country in which the study was conducted and confirmation of diagnosis. The results were compared and any disagreement was discussed and resolved by consensus.

\section{Quality evaluation}

All the studies included satisfied all the following criteria: they 1) were association studies between any of the three polymorphisms in the CTLA-4 gene and T1D;2) used diseasefree subjects as controls; 3 ) provided genotype or allele distribution in both case and control groups; 4) were independent studies and the subject groups investigated did not overlap with each other; 5) were published in peer-reviewed journals and were indexed by PubMed or cited by articles indexed by PubMed. Authors were contacted where clarification was required. 
Table 1. Characteristics of the studies included.

\begin{tabular}{|c|c|c|c|c|c|c|c|}
\hline & Study & Year & Country(ies) & Racial descent & Polymorphisms & Case & Control \\
\hline 1 & Nistico et al. & 1996 & Belgium & European & $+49 \mathrm{~A} / \mathrm{G}$ & 483 & 529 \\
\hline 2 & Donner et al. & 1997 & Germany and Canada & European & $+49 \mathrm{~A} / \mathrm{G}$ & 293 & 325 \\
\hline 3 & Van der Auwera et al. & 1997 & Belgium & European & $+49 \mathrm{~A} / \mathrm{G}$ & 525 & 530 \\
\hline 4 & Krokowski et al. & 1998 & Poland & European & $+49 \mathrm{~A} / \mathrm{G}$ & 192 & 136 \\
\hline 5 & Djilali-Saiah et al. & 1998 & France & European & $+49 \mathrm{~A} / \mathrm{G}$ & 112 & 100 \\
\hline 6 & Awata et al. & 1998 & Japan & Asian & $+49 \mathrm{~A} / \mathrm{G}$ & 173 & 425 \\
\hline 7 & Yanagawa et al. & 1999 & Japan & Asian & $+49 \mathrm{~A} / \mathrm{G}$ & 110 & 200 \\
\hline 8 & Hayashi et al. & 1999 & Japan & Asian & $+49 \mathrm{~A} / \mathrm{G}$ & 117 & 141 \\
\hline 9 & Abe et al. & 1999 & Japan & Asian & $+49 \mathrm{~A} / \mathrm{G}$ & 111 & 445 \\
\hline 10 & Takara et al. & 2000 & Japan & Asian & $+49 \mathrm{~A} / \mathrm{G}$ & 74 & 107 \\
\hline 11 & Lee et al. & 2000 & China & Asian & $+49 \mathrm{~A} / \mathrm{G}$ & 253 & 91 \\
\hline 12 & Ihara et al. & 2001 & Japan & Asian & $+49 \mathrm{~A} / \mathrm{G}$ & 160 & 200 \\
\hline 13 & Kamoun Abid et al. & 2001 & Tunisia & North African & $+49 \mathrm{~A} / \mathrm{G}$ & 74 & 48 \\
\hline 14 & Osei-Hyiaman-1 et al. & 2001 & China & Asian & $+49 \mathrm{~A} / \mathrm{G}$ & 350 & 420 \\
\hline 15 & Osei-Hyiaman-2 et al. & 2001 & Ghana & African & $+49 \mathrm{~A} / \mathrm{G}$ & 182 & 201 \\
\hline 16 & McCormack et al. & 2001 & Northern Ireland & European & $+49 \mathrm{~A} / \mathrm{G}$ & 130 & 307 \\
\hline 17 & Kikuoka et al. & 2001 & Japan & Asian & $+49 \mathrm{~A} / \mathrm{G}$ & 125 & 200 \\
\hline 18 & Cosentino et al. & 2002 & Italy & European & $+49 \mathrm{~A} / \mathrm{G}$ & 80 & 85 \\
\hline 19 & Fajardy et al. & 2002 & France & European & $+49 \mathrm{~A} / \mathrm{G}$ & 134 & 273 \\
\hline 20 & Cinek et al. & 2002 & Czech Republic & European & $+49 \mathrm{~A} / \mathrm{G}$ & 305 & 289 \\
\hline 21 & Ma et al. & 2002 & China & Asian & $+49 \mathrm{~A} / \mathrm{G}$ & 31 & 36 \\
\hline 22 & Klitz et al. & 2002 & United States & Pacific Asian & $+49 \mathrm{~A} / \mathrm{G}$ & 90 & 94 \\
\hline 23 & Wood et al. & 2002 & Germany & European & $+49 \mathrm{~A} / \mathrm{G}$ & 176 & 220 \\
\hline 24 & Ongagna et al. & 2002 & France & European & $+49 \mathrm{~A} / \mathrm{G}$ & 62 & 84 \\
\hline 25 & Mochizuki et al. & 2003 & Japan & Asian & $+49 \mathrm{~A} / \mathrm{G}$ & 97 & 60 \\
\hline 26 & Bouqbis et al. & 2003 & Morocco & African & $+49 \mathrm{~A} / \mathrm{G}$ & 118 & 114 \\
\hline 27 & Zalloua et al. & 2004 & Lebanon & Middle Eastern & $+49 \mathrm{~A} / \mathrm{G}$ & 190 & 96 \\
\hline 28 & Haller et al. & 2004 & Estonia & European & $+49 \mathrm{~A} / \mathrm{G}$ & 69 & 158 \\
\hline 29 & Ide et al. & 2004 & Japan & Asian & $+49 \mathrm{~A} / \mathrm{G}$ & 116 & 114 \\
\hline 30 & BaniaSadi et al. & 2006 & India & North Indians & $\begin{array}{l}+49 \mathrm{~A} / \mathrm{G}, \mathrm{CT} 60 \mathrm{~A} / \mathrm{G} \\
-318 \mathrm{C} / \mathrm{T}\end{array}$ & 130 & 180 \\
\hline 31 & Ahmedov et al. & 2006 & Azerbaijan & Asian & $+49 \mathrm{~A} / \mathrm{G}$ & 160 & 271 \\
\hline 32 & Ikegami et al. & 2006 & Japan & Asian & $+49 \mathrm{~A} / \mathrm{G}, \mathrm{CT} 60 \mathrm{~A} / \mathrm{G}$ & 769 & 723 \\
\hline 33 & Saleh et al. & 2008 & Egyptian & African & $+49 \mathrm{~A} / \mathrm{G}$ & 396 & 396 \\
\hline 34 & Douroudis-1 et al. & 2009 & Estonia & European & $+49 \mathrm{~A} / \mathrm{G}, \mathrm{CT} 60 \mathrm{~A} / \mathrm{G}$ & 170 & 230 \\
\hline 35 & Douroudis-2 et al. & 2009 & Finland & European & $+49 \mathrm{~A} / \mathrm{G}, \mathrm{CT} 60 \mathrm{~A} / \mathrm{G}$ & 404 & 725 \\
\hline 36 & Balic et al. & 2009 & Santiago & American & $+49 \mathrm{~A} / \mathrm{G},-318 \mathrm{C} / \mathrm{T}$ & 300 & 310 \\
\hline 37 & Jung et al. & 2009 & Korea & Asian & $+49 \mathrm{~A} / \mathrm{G},-318 \mathrm{C} / \mathrm{T}$ & 176 & 90 \\
\hline 38 & Korolija et al. & 2009 & Croatia & European & $+49 \mathrm{~A} / \mathrm{G}$ & 102 & 193 \\
\hline 39 & Ferreira et al. & 2009 & Brazil & American & $+49 \mathrm{~A} / \mathrm{G}$ & 49 & 48 \\
\hline 40 & Benmansour et al. & 2010 & Tunisia & African & $\begin{array}{l}+49 \mathrm{~A} / \mathrm{G}, \mathrm{CT} 60 \mathrm{~A} / \mathrm{G} \\
-318 \mathrm{C} / \mathrm{T}\end{array}$ & 228 & 193 \\
\hline 41 & Ei Wafai et al. & 2011 & Lebanon & Asian & $+49 \mathrm{~A} / \mathrm{G}$ & 39 & 46 \\
\hline 42 & Philip and Isabel & 2011 & Southern India & Asian & $+49 \mathrm{~A} / \mathrm{G}$ & 53 & 53 \\
\hline 43 & Mosaad et al. & 2012 & Egyptian & African & $+49 \mathrm{~A} / \mathrm{G}$ & 104 & 78 \\
\hline
\end{tabular}

\section{Statistical analysis}

The meta-analysis examined the overall association of alleles and genotypes and the risk of T1D for each polymorphism. The effect size was represented by OR with 95\%CI. The Cochran Q statistic and $\mathrm{I}^{2}$ test were used to assess heterogeneity in combined studies. Publication bias was checked using the Begg test, and the Egger test was used for funnel plot asymmetry. Both the random effect model and the fixed effect model were used to calculate pooled OR with Woolf $95 \%$ CI. P values of overall OR were generated using the $\mathrm{Z}$ test. Sensitivity analysis was conducted by removing each study and analyzing the others to ensure no single study was totally responsible for the overall results. The significance level was set at 0.05 , and all $\mathrm{P}$ values were two-tailed. We used inverted funnel plots and the BeggMazumdar publication bias diagnostics (nonparametric s correlation coefficient) to evaluate whether the magnitudes of the observed associations were related to the variance of each study. The meta-analysis was performed using Comprehensive Meta Analysis software (Version 2.2.046, BIOSTAT, Englewood, NJ, USA). 


\section{RESULTS}

The combined search yielded more than 200 references. After discarding overlapping references and those that clearly did not meet the criteria, 86 references were retained. These references were then filtered to ensure conformity with the inclusion criteria. Thirty-eight references were excluded because they were not studies referring to humans, and 5 references were excluded because they did not contain the $+49 \mathrm{~A} / \mathrm{G}$ polymorphism. Finally, 43 studied the $+49 \mathrm{~A} / \mathrm{G}$ (rs231775) variant (Table 1).

\section{Allelic analysis}

The eligible studies for analysis included 8021 cases and 9570 controls available for analysis of the $+49 \mathrm{~A} / \mathrm{G}$ polymorphism (Table 1 ). The meta-analysis of all the studies on the $+49 \mathrm{~A} / \mathrm{G}$ polymorphism was significantly associated with T1D [fixed: OR and 95\%CI: 1.326 (1.254-1.402), $\mathrm{P}<0.001$; random: OR and 95\%CI: 1.382 (1.257-1.519), $\mathrm{P}<0.001$ ] (Figure 1 and Figure $\mathrm{S} 1$ ).

\section{+49A/G Meta-Analysis}

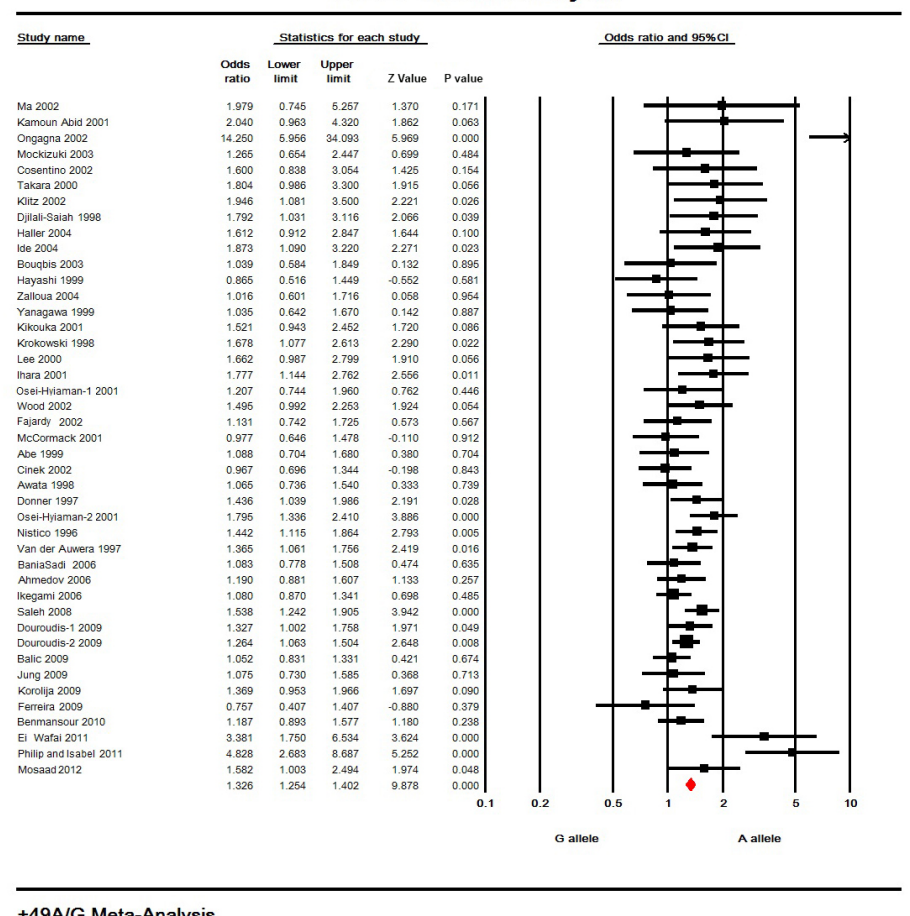

Figure 1. Meta-analysis of association studies of the $+49 \mathrm{~A} / \mathrm{G}$ polymorphism and diabetes (fixed model). Pooled overall OR is shown. The OR of each study is marked with a black square. Pooled OR is indicated by a red diamond.

When divided into 4 subgroups (6 studies in Africans, 19 studies in Asians, 3 studies in Americans and 15 studies in Europeans), except for the American subgroup, the results also showed significant association. \{Africans: [fixed/random: OR and 95\%CI: $1.392(1.205-1.608), \mathrm{P}<0.001]$ \} (Figure 2A). \{Asians: [fixed: OR and 95\%CI: 1.355 (1.230-1.493), $\mathrm{P}<0.001$; random: OR and 
95\%CI: 1.457 (1.266-1.732), P < 0.001] (Figure 2B, C). \{Europeans: [fixed: OR and 95\%CI: 1.352 (1.241-1.473), $\mathrm{P}<0.001$; random: OR and 95\%CI: 1.424 (1.219-1.664), $\mathrm{P}<0.001]\}$ (Figure 2D, E). \{Americans: [fixed/random: OR and 95\%CI: 1.031 (0.859-1.239), $\mathrm{P}=0.741]$ \} (Figure 2F).

A

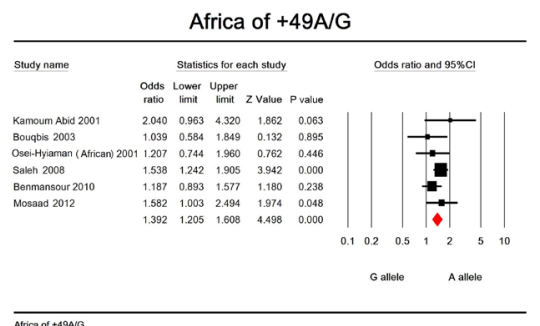

B

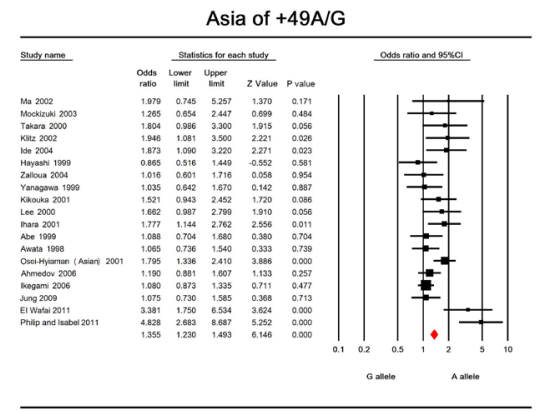

C

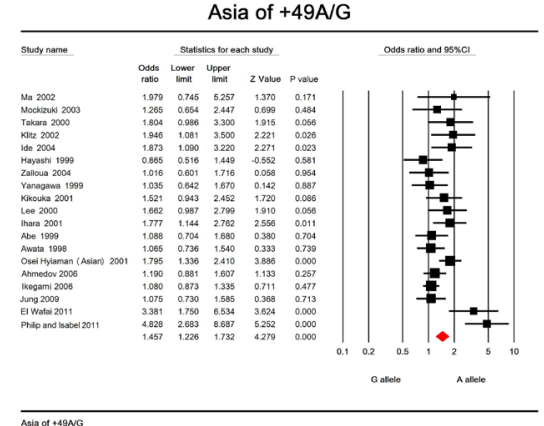

D

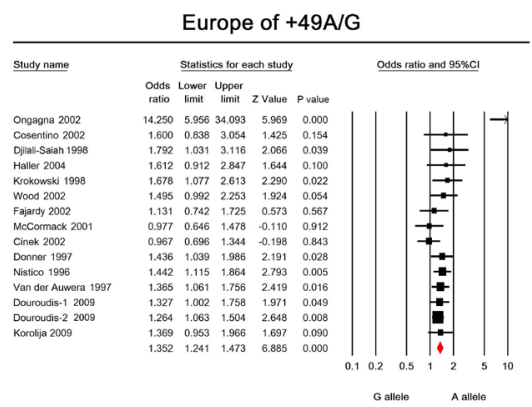

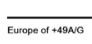

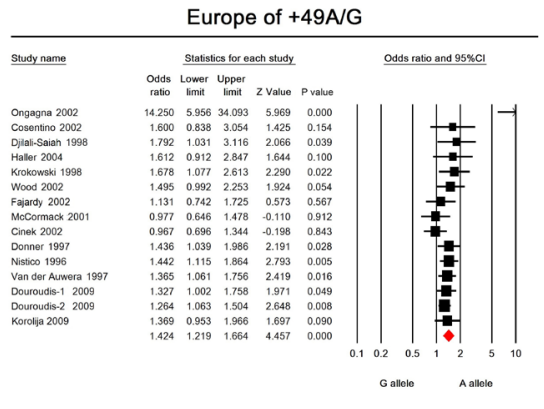

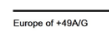

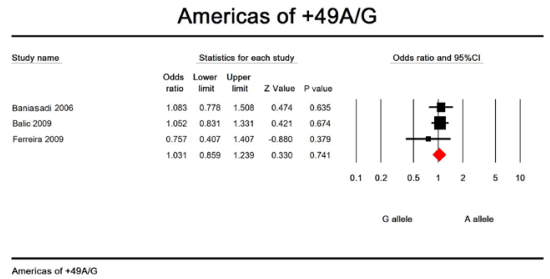

Figure 2. A. Meta-analysis of association studies of the $+49 \mathrm{~A} / \mathrm{G}$ polymorphism of Africa population and diabetes (fixed/ random models). Pooled overall OR is shown. The OR of each study is marked with a black square. Pooled OR is indicated by a red diamond. B. Meta-analysis of association studies of the $+49 \mathrm{~A} / \mathrm{G}$ polymorphism of Asia population and diabetes (fixed model). Pooled overall OR is shown. The OR of each study is marked with a black square. Pooled OR is indicated by a red diamond. C. Meta-analysis of association studies of the $+49 \mathrm{~A} / \mathrm{G}$ polymorphism of Asia population and diabetes (random model). Pooled overall OR is shown. The OR of each study is marked with a black square. Pooled $\mathrm{OR}$ is indicated by a red diamond. D. Meta-analysis of association studies of the $+49 \mathrm{~A} / \mathrm{G}$ polymorphism of Europe population and diabetes (fixed model). Pooled overall OR is shown. The OR of each study is marked with a black square. Pooled OR is indicated by a red diamond. E. Meta-analysis of association studies of the $+49 \mathrm{~A} / \mathrm{G}$ polymorphism of Europe population and diabetes (random model). Pooled overall OR is shown. The OR of each study is marked with a black square. Pooled OR is indicated by a red diamond. F. Meta-analysis of association studies of the $+49 \mathrm{~A} / \mathrm{G}$ polymorphism of Americas population and diabetes (fixed/random models). Pooled overall OR is shown. The OR of each study is marked with a black square. Pooled OR is indicated by a red diamond. 
A sensitivity analysis was carried out and the data are shown in Figure 3. The sensitivity analysis showed that when any one of the studies was removed, the heterogeneity of the population was not significantly changed, indicating that no heterogeneity existed in the population. There was no evidence that the magnitude of the overall OR estimates changed in the same direction over time. Also, the Egger funnel plots of publication bias analysis for the $+49 \mathrm{~A} / \mathrm{G}$ (rs231775) polymorphism are shown. (Figure 4).

\section{Genotypic analysis}

For the genotype analysis of $+49 \mathrm{~A} / \mathrm{G}$, the result of $\mathrm{GG}$ versus (GA+AA) was significant $\{\mathrm{OR}$ and $95 \% \mathrm{CI}: 1.558(1.432-1.696)\}$, indicating that the GG genotype was deleterious for people with T1D (Figure 5).

+49AG Meta-Analysis

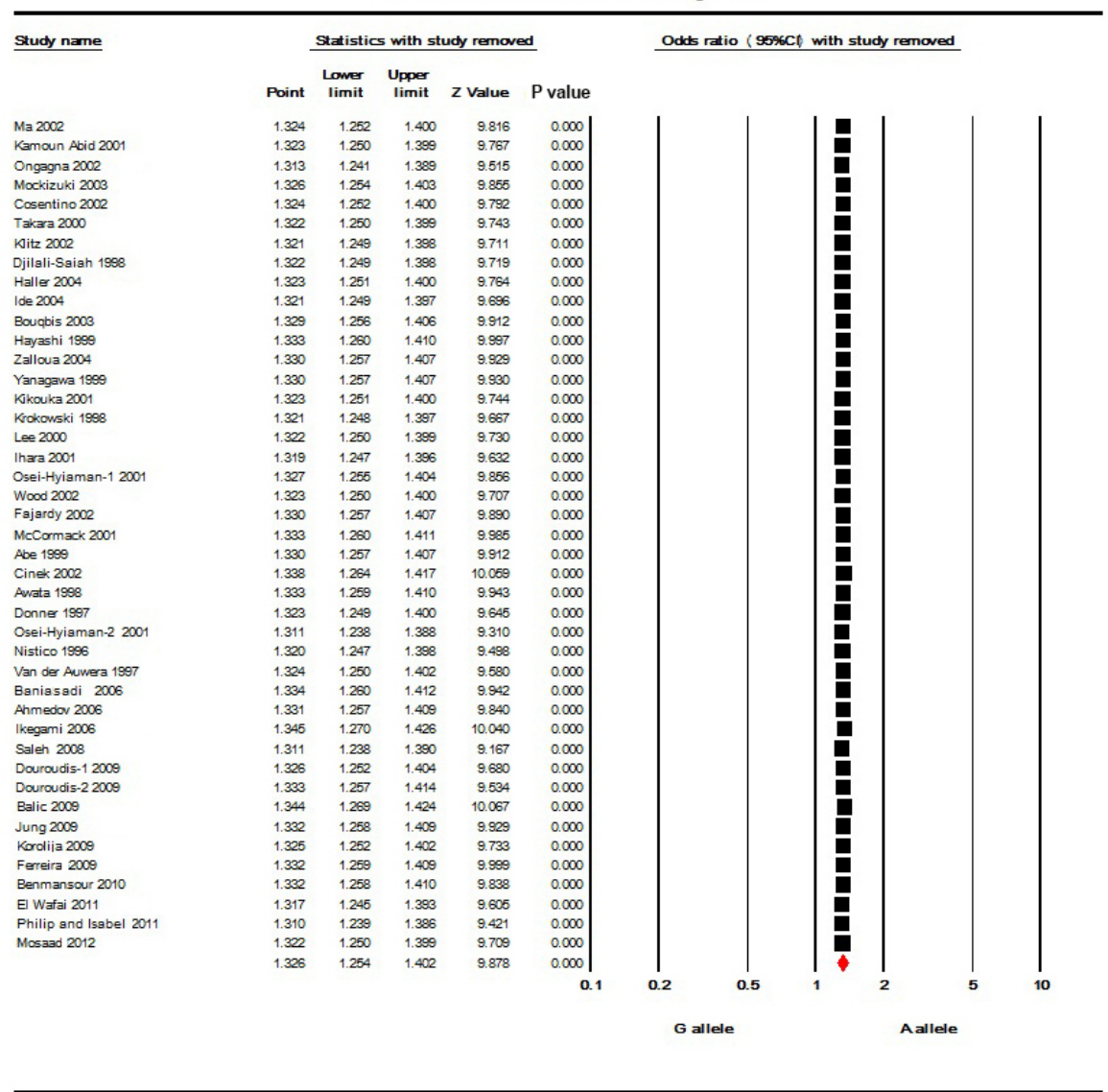

+49AG Meta-Analysis

Figure 3. Sensitivity analysis of $+49 \mathrm{~A} / \mathrm{G}$. When any one of the studies was removed, the heterogeneity of the population remained unchanged. 


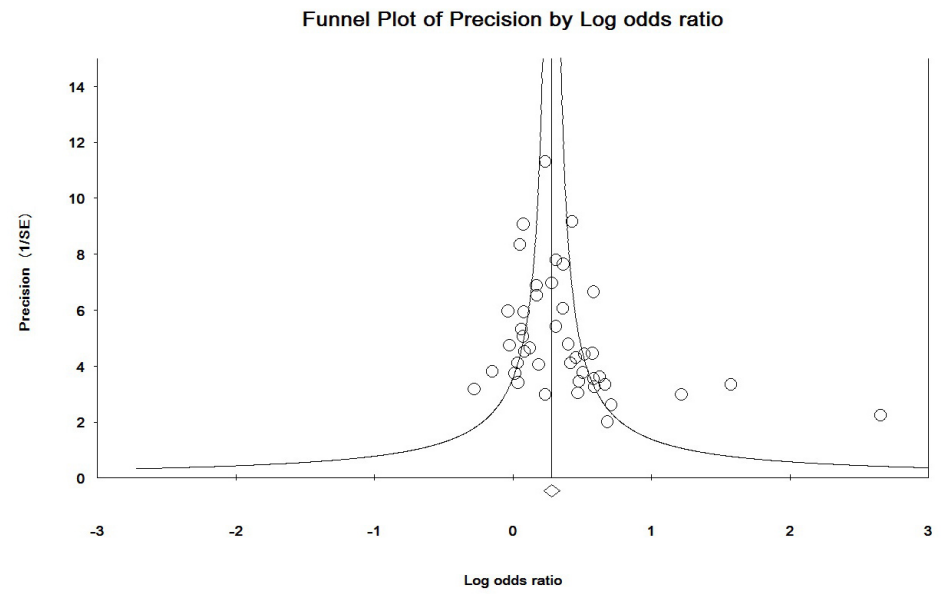

Figure 4. Egger's funnel plots of publication bias analysis for the $+49 \mathrm{~A} / \mathrm{G}$ polymorphism. The larger the deviation from the funnel curve of each study, the more pronounced the asymmetry. Results from small studies scatter widely at the bottom of the graph, with the spread narrowing among larger studies.

\section{GG/ ( GA+AA) of +49A/G}

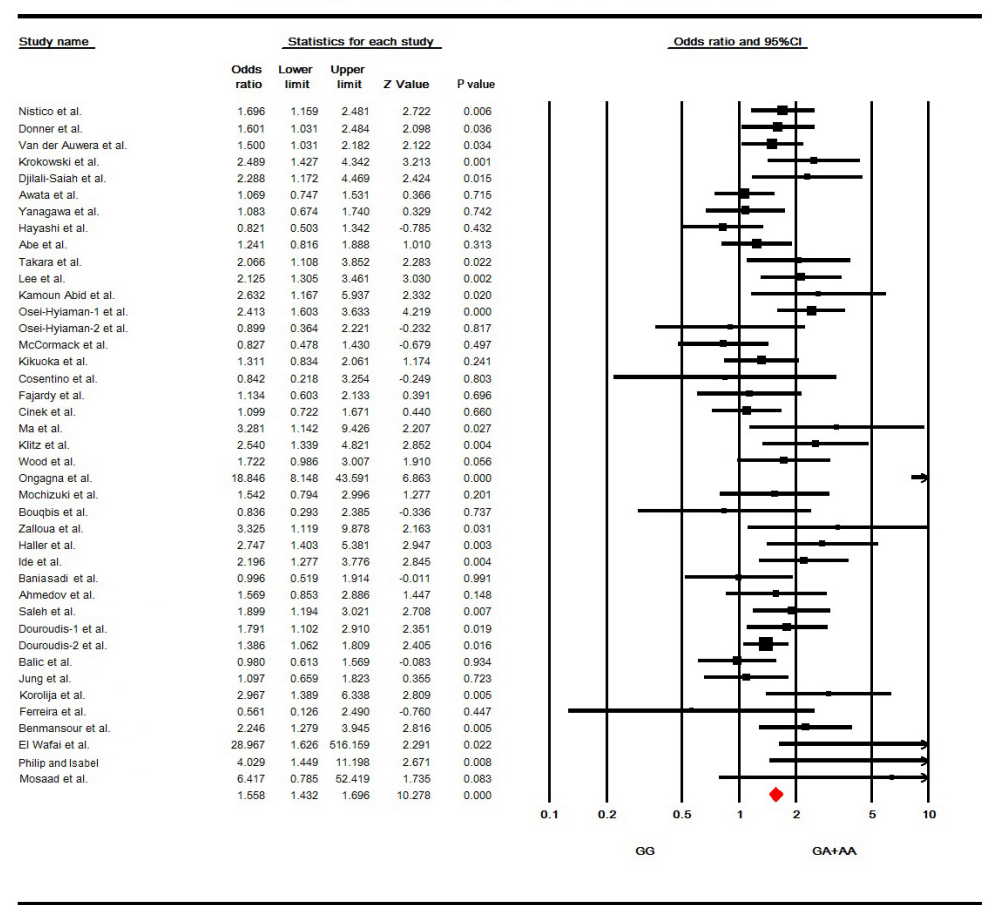

GG/ ( $A G+A A)$ of +49 A/G

Figure 5. Meta-analysis of association studies of the $+49 \mathrm{~A} / \mathrm{G} \mathrm{GG} /(\mathrm{GA}+\mathrm{AA})$ and diabetes. Pooled overall OR is shown. The OR of each study is marked with a black square. Pooled OR is indicated by a red diamond. 


\section{DISCUSSION}

T1D is commonly considered to be an organ-specific autoimmune disorder with a multifactorial background, where onset is preceded by a period of autoimmune destruction of the insulin-producing pancreatic $\beta$-cells and with high levels of IFN- $\gamma$ and TNF- $\beta$ (Atkinson and Eisenbarth, 2001). In addition, it is a heterogeneous syndrome with considerable variability in age of onset, abruptness of onset, and autoantibody profile. However the pathogenesis of the development and progression of T1D is far from clear at present. Because of the various and serious lifelong complications of T1D, it is crucial to identify the etiologic factors in the pathogenesis of this disease. The major histocompatibility complex region explains approximately half of the genetic susceptibility to T1D, suggesting that additional determinants exist, and such determinants are suggested repeatedly by different genome scans (Polychronakos and Li, 2011).

A number of studies have indicated that variants of the CTLA-4 gene may contribute to the disease. Fine mapping analyses have also suggested that peak linkage and association are present in the CTLA-4 region $(+49 \mathrm{~A} / \mathrm{G},-819 \mathrm{C} / \mathrm{T}$, and (AT)n in the 3'UTR) (Marron et al., 1997). However, the results of genetic association studies have been confusing because of the difficulty in replicating significant associations. Different characteristics among studies such as ethnicities, diabetes mellitus type, and definition of case and control have introduced heterogeneity and made the results of association studies hard to interpret.

In this study, we performed a comprehensive meta-analysis aimed at identifying the origin of heterogeneity and assessing the overall effects of these variants on T1D. This comprehensive meta-analysis included data from 43 studies with approximately 17,591 T1D cases and controls. It revealed significant evidence of association between the CTLA-4 gene and T1D. The $+49 \mathrm{~A} / \mathrm{G}$ polymorphism showed both an overall association and subgroup associations, except for the American subgroup. The $G$ allele in overall populations and subgroup populations, and the GG genotype showed a positive association with T1D. One explanation is that $+49 \mathrm{~A} / \mathrm{G}$ may have a significant effect on the disease, and may be in LD with other causative mutations.

Given the limitations and potential biases in the study, the results of our meta-analysis should be treated with caution. Overall, we did not detect substantial publication bias. However, since we included only studies published in English, there may have been a language bias. In addition, most of the included studies were retrospective. Also, it was not possible to take into account some environmental factors such as lifestyle and diet.

In conclusion, the current comprehensive meta-analysis pooled larger sample sizes analyzing them both together and separately. The design of systematic methods and analytical approaches as well as heterogeneity tests and sensitivity analyses produced more significant results. These findings demonstrated the robustness of the association between both the allele and genotype of the $+49 \mathrm{~A} / \mathrm{G}$ polymorphism of the CTLA-4 gene and T1D, an association which was significant in multiple studies. T1D is caused by the combined actions of many factors. Thus, for greater insight into its genetic components, more work is required to confirm the role of other genes that may have a small individual effect, and to identify new genetic risk factors. The large samples required will necessitate multi-site projects and meta-analyses on the basis of national and international collaboration.

\section{Conflicts of interest}

The authors declare no conflict of interest. 


\section{ACKNOWLEDGMENTS}

Research supported by the "973" Program (\#2010CB529600), the "863" Program (\#2012AA02A515), the National Key Technology R\&D Program (\#2006BAI05A09, \#2012BAI01B09), the National Nature Science Foundation of China (\#81121001, \#81130022, \#31000553), the Shanghai Municipal Commission of Science and Technology Program (\#09DJ1400601), the Shanghai Leading Academic Discipline Project (B205), the National Natural Science Foundation of China (\#31000408) and the Shanghai Education Committee for Young Teachers (\#jdy10001).

\section{Supplementary material}

\section{REFERENCES}

Abe T, Takino H, Yamasaki H, Ozaki M, et al. (1999). CTLA4 gene polymorphism correlates with the mode of onset and presence of ICA512 Ab in Japanese type 1 diabetes. Diabetes Res. Clin. Pract. 46: 169-175.

Ahmedov G, Ahmedova L, Sedlakova P and Cinek O (2006). Genetic association of type 1 diabetes in an Azerbaijanian population: the HLA-DQ, -DRB1*04, the insulin gene, and CTLA4. Pediatr. Diabetes 7: 88-93.

Atkinson MA and Eisenbarth GS (2001). Type 1 diabetes: new perspectives on disease pathogenesis and treatment. Lancet 358: 221-229.

Awata T, Kurihara S, Iitaka M, Takei S, et al. (1998). Association of CTLA-4 gene A-G polymorphism (IDDM12 locus) with acute-onset and insulin-depleted IDDM as well as autoimmune thyroid disease (Graves' disease and Hashimoto's thyroiditis) in the Japanese population. Diabetes 47: 128-129.

Balic I, Angel B, Codner E, Carrasco E, et al. (2009). Association of CTLA-4 polymorphisms and clinical-immunologic characteristics at onset of type 1 diabetes mellitus in children. Hum. Immunol. 70: 116-120.

Baniasadi V, Narain N, Goswami R and Das SN (2006). Promoter region -318 C/T and -1661 A/G CTLA-4 single nucleotide polymorphisms and type 1 diabetes in North Indians. Tissue Antigens 67: 383-389.

Benmansour J, Stayoussef M, Al-Jenaidi FA, Rajab MH, et al. (2010). Association of single nucleotide polymorphisms in cytotoxic T-lymphocyte antigen 4 and susceptibility to autoimmune type 1 diabetes in Tunisians. Clin. Vaccine Immunol. 17: 1473-1477.

Bouqbis L, Izaabel H, Akhayat O, Perez-Lezaun A, et al. (2003). Association of the CTLA4 promoter region (-1661G allele) with type 1 diabetes in the South Moroccan population. Genes Immun. 4: 132-137.

Cinek O, Drevinek P, Sumnik Z, Bendlova B, et al. (2002). The CTLA4 +49 A/G dimorphism is not associated with type 1 diabetes in Czech children. Eur. J. Immunogenet. 29: 219-222.

Cosentino A, Gambelunghe G, Tortoioli C and Falorni A (2002). CTLA-4 gene polymorphism contributes to the genetic risk for latent autoimmune diabetes in adults. Ann. N. Y. Acad. Sci. 958: 337-340.

Djilali-Saiah I, Larger E, Harfouch-Hammoud E, Timsit J, et al. (1998). No major role for the CTLA-4 gene in the association of autoimmune thyroid disease with IDDM. Diabetes 47: 125-127.

Donner H, Rau H, Walfish PG, Braun J, et al. (1997). CTLA4 alanine-17 confers genetic susceptibility to Graves' disease and to type 1 diabetes mellitus. J. Clin. Endocrinol. Metab. 82: 143-146.

Douroudis K, Laine AP, Heinonen M, Hermann R, et al. (2009). Association of CTLA4 but not ICOS polymorphisms with type 1 diabetes in two populations with different disease rates. Hum. Immunol. 70: 536-539.

Ei Wafai RJ, Chmaisse HN, Makki RF and Fakhoury H (2011). Association of HLA class II alleles and CTLA-4 polymorphism with type 1 diabetes. Saudi J. Kidney Dis. Transpl. 22: 273-281.

Fajardy I, Vambergue A, Stuckens C, Weill J, et al. (2002). CTLA-4 49 A/G dimorphism and type 1 diabetes susceptibility: a French case-control study and segregation analysis. Evidence of a maternal effect. Eur. J. Immunogenet. 29: 251-257.

Ferreira AC, Gomes KB, Sampaio IB, Oliveira VC, et al. (2009). Type 1 diabetes susceptibility determined by HLA alleles and CTLA-4 and insulin genes polymorphisms in Brazilians. Arq. Bras. Endocrinol. Metabol. 53: 368-373.

Greenwald RJ, Oosterwegel MA, van der Woude D, Kubal A, et al. (2002). CTLA-4 regulates cell cycle progression during a primary immune response. Eur. J. Immunol. 32: 366-373.

Haller K, Kisand K, Nemvalts V, Laine AP, et al. (2004). Type 1 diabetes is insulin -2221 MspI and CTLA-4 +49 A/G polymorphism dependent. Eur. J. Clin. Invest. 34: 543-548. 
Hayashi H, Kusaka I, Nagasaka S, Kawakami A, et al. (1999). Association of CTLA-4 polymorphism with positive antiGAD antibody in Japanese subjects with type 1 diabetes mellitus. Clin. Endocrinol. 51: 793-799.

Ide A, Kawasaki E, Abiru N, Sun F, et al. (2004). Association between IL-18 gene promoter polymorphisms and CTLA-4 gene 49A/G polymorphism in Japanese patients with type 1 diabetes. J. Autoimmun. 22: 73-78.

Ihara K, Ahmed S, Nakao F, Kinukawa N, et al. (2001). Association studies of CTLA-4, CD28, and ICOS gene polymorphisms with type 1 diabetes in the Japanese population. Immunogenetics 53: 447-454.

Ikegami H, Awata T, Kawasaki E, Kobayashi T, et al. (2006). The association of CTLA4 polymorphism with type 1 diabetes is concentrated in patients complicated with autoimmune thyroid disease: a multicenter collaborative study in Japan. J. Clin. Endocrinol. Metab. 91: 1087-1092.

Jung MH, Yu J, Shin CH, Suh BK, et al. (2009). Association of cytotoxic T lymphocyte antigen-4 gene polymorphisms and HLA class II alleles with the development of type 1 diabetes in Korean children and adolescents. J. Korean Med. Sci. 24: 1004-1009.

Kamoun AH, Hmida S, Smaoui N, Kaabi H, et al. (2001). Association between type 1 diabetes and polymorphism of the CTLA-4 gene in a Tunisian population. Pathol. Biol. 49: 794-798.

Kikuoka N, Sugihara S, Yanagawa T, Ikezaki A, et al. (2001). Cytotoxic T lymphocyte antigen 4 gene polymorphism confers susceptibility to type 1 diabetes in Japanese children: analysis of association with HLA genotypes and autoantibodies. Clin. Endocrinol. 55: 597-603.

Klitz W, Bugawan TL, Panelo A, Solfelix CM, et al. (2002). Association of CTLA-4 variation with type I diabetes in Filipinos. Immunogenetics 54: 310-313.

Korolija M, Renar IP, Hadzija M, Medvidovic EP, et al. (2009). Association of PTPN22 C1858T and CTLA-4 A49G polymorphisms with Type 1 Diabetes in Croatians. Diabetes Res. Clin. Pract. 86: e54-e57.

Krokowski M, Bodalski J, Bratek A, Machejko P, et al. (1998). CTLA-4 gene polymorphism is associated with predisposition to IDDM in a population from central Poland. Diabetes Metab. 24: 241-243.

Lee YJ, Huang FY, Lo FS, Wang WC, et al. (2000). Association of CTLA4 gene A-G polymorphism with type 1 diabetes in Chinese children. Clin. Endocrinol. 52: 153-157.

Leung HT and Linsley PS (1994). The CD28 costimulatory pathway. Ther. Immunol. 1: 217-228.

Ma Y, Tang X, Chang W, Gao L, et al. (2002). CTLA-4 gene A/G polymorphism associated with diabetes mellitus in Han Chinese. Chin. Med. J. 115: 1248-1250.

Marron MP, Raffel LJ, Garchon HJ, Jacob CO, et al. (1997). Insulin-dependent diabetes mellitus (IDDM) is associated with CTLA4 polymorphisms in multiple ethnic groups. Hum. Mol. Genet. 6: 1275-1282.

McCormack RM, Maxwell AP, Carson D, Patterson CC, et al. (2001). Possible association between CTLA4 DNA polymorphisms and early onset type 1 diabetes in a UK population. Genes Immun. 2: 233-235.

Mochizuki M, Amemiya S, Kobayashi K, Kobayashi K, et al. (2003). Association of the CTLA-4 gene 49A/G polymorphism with type 1 diabetes and autoimmune thyroid disease in Japanese children. Diabetes Care 26: 843-847.

Mosaad YM, Elsharkawy AA and El-Deek BS (2012). Association of CTLA-4 (+49A/G) gene polymorphism with type 1 diabetes mellitus in Egyptian children. Immunol. Invest. 41: 28-37.

Nistico L, Buzzetti R, Pritchard LE, Van der Auwera B, et al. (1996). The CTLA-4 gene region of chromosome 2q33 is linked to, and associated with, type 1 diabetes. Belgian Diabetes Registry. Hum. Mol. Genet. 5: 1075-1080.

Ongagna JC, Sapin R, Pinget M and Belcourt A (2002). Markers for risk of type 1 diabetes in relatives of Alsacian patients with type 1 diabetes. Int. J. Exp. Diabetes Res. 3: 1-9.

Osei-Hyiaman D, Hou L, Zhiyin R, Zhiming Z, et al. (2001). Association of a novel point mutation (C159G) of the CTLA4 gene with type 1 diabetes in West Africans but not in Chinese. Diabetes 50: 2169-2171.

Philip B and Isabel W (2011). Association of cytotoxic T lymphocyte-associated antigen 4 gene single nucleotide polymorphism with type 1 diabetes mellitus in Madurai population of Southern India. Indian J. Hum. Genet. 17: 85-89.

Polychronakos C and Li Q (2011). Understanding type 1 diabetes through genetics: advances and prospects. Nat. Rev. Genet. 12: 781-792.

Saleh HM, Rohowsky N and Leski M (2008). The CTLA4 -819 C/T and +49 A/G dimorphisms are associated with Type 1 diabetes in Egyptian children. Indian J. Hum. Genet. 14: 92-98.

Takara M, Komiya I, Kinjo Y, Tomoyose T, et al. (2000). Association of CTLA-4 gene A/G polymorphism in Japanese type 1 diabetic patients with younger age of onset and autoimmune thyroid disease. Diabetes Care 23: 975-978.

Van der Auwera BJ, Vandewalle CL, Schuit FC, Winnock F, et al. (1997). CTLA-4 gene polymorphism confers susceptibility to insulin-dependent diabetes mellitus (IDDM) independently from age and from other genetic or immune disease markers. Clin. Exp. Immunol. 110: 98-103.

Wood JP, Pani MA, Bieda K, Meyer G, et al. (2002). A recently described polymorphism in the CD28 gene on chromosome $2 \mathrm{q} 33$ is not associated with susceptibility to type 1 diabetes. Eur. J. Immunogenet. 29: 347-349. 
Yanagawa T, Maruyama T, Gomi K, Taniyama M, et al. (1999). Lack of association between CTLA-4 gene polymorphism and IDDM in Japanese subjects. Autoimmunity 29: 53-55.

Zalloua PA, Abchee A, Shbaklo H, Zreik TG, et al. (2004). Patients with early onset of type 1 diabetes have significantly higher GG genotype at position 49 of the CTLA4 gene. Hum. Immunol. 65: 719-724. 